\title{
Tropospheric Comparisons of Vaisala Radiosondes and Balloon-Borne Frost-Point and Lyman- $\alpha$ Hygrometers during the LAUTLOS-WAVVAP Experiment
}

\author{
T. M. SuOrtti,* A. Kats, ${ }^{+}$R. Kivi,* N. KäMPfer,\# U. Leiterer, ${ }^{@}$ L. M. Miloshevich, \& \\ R. Neuber,** A. PAukKunen, ${ }^{++}$P. RupPert, ${ }^{* \#}$ H. VÖMEL, ${ }^{@} @$ AND V. YushKov ${ }^{+}$ \\ *Arctic Research Centre, Finnish Meteorological Institute, Sodankylä, Finland \\ + Central Aerological Observatory, Dolgoprundy, Russia \\ \# Institute of Applied Physics, University of Bern, Bern, Switzerland \\ @ Meteorological Observatory Lindenberg, German Weather Service, Lindenberg, Germany \\ \& National Center for Atmospheric Research, Boulder, Colorado \\ **Alfred Wegener Institute, Potsdam, Germany \\ ++ Vaisala Oyj, Helsinki, Finland \\ \#\# Meteolabor AG, Wetzikon, Switzerland \\ @@CIRES, University of Colorado, Boulder, Colorado
}

(Manuscript received 6 July 2006, in final form 9 March 2007)

\begin{abstract}
The accuracy of all types of Vaisala radiosondes and two types of Snow White chilled-mirror hygrosondes was assessed in an intensive in situ comparison with reference hygrometers. Fourteen nighttime reference comparisons were performed to determine a working reference for the radiosonde comparisons. These showed that the night version of the Snow White agreed best with the references [i.e., the NOAA frost-point hygrometer (FPH) and University of Colorado cryogenic frost-point hygrometer $(\mathrm{CFH})]$, but that the daytime version had severe problems with contamination in the humid upper troposphere. Since the RS92 performance was superior to the other radiosondes and to the day version of the Snow White, it was selected to be the working reference. According to the reference comparison, the RS92 has no bias in the mid- and lower troposphere, with deviations $< \pm 5 \%$ in relative humidity $(\mathrm{RH})$. In the upper troposphere, the RS92 has a $\sim 5 \% \mathrm{RH}$ wet bias, which is partly due to the RS92 time lag error and the termination of the heating cycle. It was shown that the time lag effects relating to Vaisala radiosondes can be corrected. Because these were nighttime comparisons, they can be considered to be free from solar radiation effects. Neither the radiosondes nor the Snow White succeeded in reproducing reference class hygrometer profiles in the stratosphere.

According to the 29 radiosonde intercomparisons, the RS92 and the modified RS90 (FN) had the best mutual agreement and no bias. The disagreement is largest $(< \pm 10 \% \mathrm{RH})$ at low temperatures $(T \ll$ $-30^{\circ} \mathrm{C}$ ), where the FN underestimated (overestimated) in high (low) ambient RH. In comparison with the RS92, the RS90 had a semilinearly increasing wet bias with decreasing temperature, where the bias was $\sim 10 \% \mathrm{RH}$ at $-60^{\circ} \mathrm{C}$. The RS80-A suffers from a large temperature-dependent dry bias in high $\mathrm{RH}$ conditions, being over $30 \% \mathrm{RH}$ at $-60^{\circ} \mathrm{C}$ and $\sim 5 \% \mathrm{RH}$ near $0^{\circ} \mathrm{C}$. The RS80-A dry bias can be almost totally removed with the correction algorithm by Leiterer et al., which was chosen as the best available. The other approach tested tends to overcorrect in high $\mathrm{RH}$ conditions when $T<-50^{\circ} \mathrm{C}$. For $T>-30^{\circ} \mathrm{C}$ it is ineffective and does not correct the RS80-A dry bias in high ambient RH.
\end{abstract}

\section{Introduction}

The Lapland Atmosphere-Biosphere Facility (LAPBIAT) Upper Troposphere Lower Stratosphere

Corresponding author address: T. M. Suortti, Arctic Research Centre, Finnish Meteorological Institute, Tähteläntie 62, 99600 Sodankylä, Finland.

E-mail: tuomo.suortti@fmi.fi
Water Vapor Validation Project (LAUTLOSWAVVAP) hygrometer intercomparison campaign was held in northern Finland at Sodankylä $\left(67.37^{\circ} \mathrm{N}\right.$, $26.65^{\circ} \mathrm{E}$ ) in February 2004. The experiment was held in high-latitude winter conditions and consisted of 33 balloon-borne multihygrometer payloads, including the following Vaisala radiosondes: RS80, RS90, and RS92, as well as the modified RS90 (FN; see the appendix for a list of acronyms), frost-point hygrometers (FPHs) by

DOI: $10.1175 / 2007 J T E C H A 887.1$ 
the Global Monitoring Division of National Oceanic and Atmospheric Administration (NOAA), the University of Colorado cryogenic frost-point hygrometer (CU-CFH), and Meteolabor Snow White, and, in addition, Fluorescent Advanced Stratospheric Hygrometer (FLASH-B) Lyman- $\alpha$ hygrometers. In addition to the balloon measurements, water vapor profiles were also measured with the Middle Atmospheric Water Vapor Radiometer (MIAWARA; Deuber et al. 2005) and supplemented with one week of airborne measurements by Airborne Microwave Stratospheric Observing System (AMSOS; Vasic et al. 2005).

The aim of the LAUTLOS experiment was to bridge the gap between old and modern measurements, as well as to improve current measurements of UT/LS water vapor. This was done by bringing together lightweight hygrometers having a potential for the study of UT/LS water vapor, and comparing them with successive generations of Vaisala radiosondes.

Behind all this is the known fact that the accuracy requirements set by climate change studies regarding water vapor measurements are hard to meet. The issue is scientifically important because water vapor is important for the radiative balance of the earth's atmosphere. Recent model calculations show that the observed water vapor increases in the stratosphere contribute significantly both to surface warming and stratospheric cooling (Forster and Shine 2002). In addition to climatic impacts, water vapor changes directly affect the ozone layer through chemistry.

In deriving the tropospheric water vapor trends for past decades, the role of radiosonde data is central, because the longest-available continuous water vapor profile information is contained in radiosounding archives. The start of digitized radiosonde records practically coincides with the International Geophysical Year 1957/58. The complication is, however, that radiosonde records are unfortunately plagued with inhomogeneities caused by instrument developments. This report aims to show the discrepancies between different Vaisala radiosonde generations from the 1980s onward, and tests the reported corrections for the RS80 relative humidity (RH). The interest shown toward the RS80 is due to the fact that the Vaisala RS80 radiosonde captured a large share of the world market, and so RS80 data archives have become valuable for climate change research.

The added value of this study is based on the following aspects. To begin with, this is the first comparison made in high-latitude winter conditions. Second, it presents new comparisons between radiosondes and scientific hygrometers by including both the RS80-A and - $\mathrm{H}$, and in addition, the $\mathrm{FN}$-sonde. The inclusion of the
TABLE 1. Instruments taking part in LAUTLOS, where RS denotes radiosonde, FPH denotes the chilled-mirror FPH, PF denotes photofluorescence, A denotes the A-Humicap, $\mathrm{H}$ denotes the H-Humicap, h denotes heated, $\mathrm{Tr}$ denotes the troposphere, and St denotes the stratosphere.

\begin{tabular}{lllcc}
\hline \hline Instrument & Type & Hygrometer & Telemetry & $\begin{array}{c}\text { Optimal } \\
\text { range }\end{array}$ \\
\hline RS80-A & RS & A & - & Tr \\
RS80-H & RS & H & - & Tr \\
RS90 & RS & Hh & - & Tr \\
RS92 & RS & Hh & - & Tr \\
FN & RS & Hh & - & Tr \\
Snow White & FPH & Optical & - & Tr \\
CU-CFH & FPH & Optical & RS80-H & St \\
NOAA-FPH & FPH & Optical & RS80-H & St \\
FLASH-B & PF & Lyman- $\alpha$ & RS80-A & St \\
\hline
\end{tabular}

RS80-A is important because it is the most widely used version of the RS80 outside the United States and United Kingdom. Additionally, these comparisons include a newer version of the RS92, as compared to earlier campaigns. From a climatological point of view, this report introduces a comparison of the two most up-to-date correction methods for the RS80-A RH.

\section{Instruments}

The list of balloon-borne instrumentation included in the comparisons during LAUTLOS is shown in Table 1. In addition, each instrument is discussed separately in the following sections.

\section{a. Humidity measurements with Vaisala radiosondes}

\section{1) RS80 RADIOSONDES}

RS80 radiosondes have been produced since 1980 . There are of two different types, equipped with planar thin-film sensors of either A- or H-Humicap polymer. The RS80-H has been available since 1990. The production calibration of the RS80-A relies on the basic calibration model (type specific) and also partly on linear temperature dependence (TD) calculation modeling. This leads to a significant dry bias in $\mathrm{RH}$ measurements in cold and humid UT conditions (Miloshevich et al. 2001; Wang et al. 2002). The temperature dependence clearly dominates as the major source of error for the RS80-A for $T \ll-20^{\circ} \mathrm{C}$. The calibration of the RS80-H is done using an H-polymer sensor-specific, basic calibration model. This is able to reduce bias errors, as reported in Miloshevich et al. (2001). However, there are some remaining issues in $\mathrm{RS} 80-\mathrm{H}$ production causing biases and an additional batch variation (Turner et al. 2003; Revercomb et al. 2003). The cali- 
bration and related corrections have remained unchanged in RS80-A production since October 1985, and in RS80-H production since 1990.

The response time of the RS80 Humicap is mainly dependent on the characteristics of the polymer, sensor, and sensor boom design. The response time is expected to increase exponentially with decreasing temperature (Miloshevich et al. 2004, 2001). The time lag error is considerably bigger for the H-Humicap. Corrections have been developed by Miloshevich et al. (2004) and Leiterer et al. (2005). In addition to the earliermentioned TD correction error, the time lag error is another major component of the observed dry bias in humid layers of the UT with the RS80 (Vömel et al. 2003).

It has been found that the old RS80 radiosondes experienced chemical contamination errors, caused by radiosonde packaging materials (Wang et al. 2002). For RS80 radiosondes produced after June 2000 this error source has been removed by using absorption material (already from September 1998) and a removable boom cover (from June 2000 onward). All RS80 instruments used during the LAUTLOS campaign were of this modern type.

Solar radiation and precipitation are also important error sources for $\mathrm{RH}$ measurements. In the RS80, the RH sensors are shielded with an aluminized protective cap to minimize the effect of these two factors. However, the arrangement does not work properly under all conditions, especially when a sonde passes through clouds with a high liquid water content. The resulting ice-contaminated sensor does not measure the true ambient RH correctly. According to Finnish radiosonde records, $20 \%$ or more of RS80 soundings may suffer from sensor icing during the winter.

Solar radiation error passes into the $\mathrm{RH}$ measurement through the TD correction and sensor boom heating. The latest change to the RS80 temperature measurement radiation correction table was included in sounding software versions released after 1 May 1993. The RSN86 correction table was then replaced with the RSN93. The new table was verified during the World Meteorological Organization (WMO) radiosonde comparison, phase IV (Tsukuba, Japan, 15 February-12 March 1993).

\section{2) RS90 RADIOSONDES}

RS90 radiosondes were in production between 1997 and 2005. The RS90 introduced a new, small-sized heated H-polymer twin sensor design (Paukkunen 1995). Because of the smaller sensor dimensions, the RH time response is faster, leading to a smaller time lag error. The RS90 has two RH sensors that are heated alternately. In the heating mode, a sensor is heated well above the boiling point of water to remove condensation. After cooling down to the ambient temperature, the sensor is used for acquiring data (the measurement mode). During this, the other sensor is heated. The alternating heating cycle is continued down to $-40^{\circ} \mathrm{C}$, where it is terminated. The heating makes the measurement considerably less vulnerable to condensation. The accuracy of the RS90 is reported in Paukkunen et al. (2001).

At the beginning of RS90 production, its TD correction was based on the RS80-H model. A new improved version came into production on 25 June 2001. This new correction was already tested in the WMO international radiosonde intercomparison (in Alcantara, Brazil, 20 May-10 June 2001). The contamination protection shield (boom cover) was not implemented in the $\mathrm{RS} 90$ radiosonde, as it had been in the RS80; this makes the RS90 more prone to chemical contamination errors. The performance of the RS90 radiosonde has been discussed in Miloshevich et al. (2006). The RS90 does not have protective rain caps over its $\mathrm{RH}$ sensors. This has increased the assembly sensitivity to solar radiation. Throughout production, only one temperature sensor solar radiation correction (RSN96) table has been used for the RS90.

\section{3) The RS92 RAdiosondes}

The RS92, the latest Vaisala radiosonde model, became available in 2005. It utilizes the same method of two heated H-Humicap sensors as the RS90, but with improvements in sensor design. The heating process of the twin sensor was optimized to better prevent sensor icing by fine-tuning the heating parameters and extending the heating down to $-60^{\circ} \mathrm{C}$ (instead of $-40^{\circ} \mathrm{C}$ ). The RS92 incorporates a reconditioning method to totally remove chemical contamination before the sounding, using the Vaisala ground check Set GC25.

Early in the RS92 production, the TD correction for the RH sensor was based on the RS90 H-Humicap model. Starting on 6 April 2004, a new version was introduced, but it was already used during the LAUTLOS experiment. The RS92 also participated in the WMO radiosonde intercomparison in Mauritius in 2005 (Nash et al. 2005) with the new TD correction. The RS92 then also included additional design improvements to minimize solar radiation heating of the RH sensor, reducing the effect to about a half of that of the earlier radiosonde version. These modifications have been introduced into production at the end of 2006. The temperature measurement solar radiation correction table RSN96 has been revised for the RS92; the new one (RSN2005) was verified in Mauritius, and 
has been available since November 2005. The dry bias introduced by solar radiation into the $\mathrm{RH}$ measurement is discussed in detail in Vömel et al. (2007b). According to them, the sensor boom heating may lead to substantial dry bias errors in conditions of strong solar radiation.

\section{b. The FN method}

An independent instrumental approach for improving RH measurements uses a modified RS90. This approach is known as the FN method, that is, the method of "standardized frequencies." It has been developed at the Lindenberg Meteorological Observatory in Germany (Leiterer et al. 1997; Nagel et al. 2001). The modified version of the RS90, that is, the FN-sonde (FN), is specially produced by Vaisala for the DWD. It has the same sensor boom, but slightly modified electronics, providing prolonged heating and measurement periods: 60 and $160 \mathrm{~s}$ instead of 40 and $104 \mathrm{~s}$. This is to compensate for the increasing response time at low temperatures. There are two types of $\mathrm{FN}$, one with heating continued down to $-52^{\circ} \mathrm{C}$, and the other with continuous heating. The latter was tested during the LAUTLOS campaign, and was proven to have a weaker performance in the UT. The second technical difference is that instead of using standard wateractivated batteries, the FN uses a customized battery assembly that ensures constant heating power during the ascent.

The main difference in the RH measurement is that in the FN method the telemetry frequencies from both of the Humicaps are received simultaneously; that is, the signal from the heated Humicap is also processed. The benefit of this is that the $0 \% \mathrm{RH}$ calibration is carried out in flight by assuming that at the end of the heating period the sensor has evaporated all the water molecules.

\section{c. Reference hygrometers}

Two types of chilled-mirror FPHs have been used in this work. The main difference between them lies in their mirror cooling methods. In the NOAA-FPH and $\mathrm{CU}-\mathrm{CFH}$ the mirror is cooled by a cryogenic liquid, while in the Snow White it is done by a Peltier element. The cooling capacity of these two methods differ: cryogenic cooling is more effective. In addition to FPHs, flights carried a Lyman- $\alpha$ hygrometer (FLASH-B). FPH measurements are considered as a reference for radiosondes because they are based on a direct measurement of a geophysical parameter, that is, the mirror temperature, and therefore, no additional sensor calibrations are needed.

The Snow White is manufactured by Meteolabor,
Switzerland, which provided two models that were used in LAUTLOS, a daytime and a nighttime version. In the daytime version, the sensor housing and radiator are enclosed in a styrofoam housing, and the air is led to the sensor via a duct to prevent solar light contamination of the optical measurement. The use of a styrofoam casing makes the daytime version prone to water vapor contamination and out-gassing problems (observed as a wet bias, especially in the UT). In the nighttime version, the sensor housing and radiator are exposed in order to minimize the potential of these problems and to maximize the cooling efficiency of the radiator. This type is only usable at night. Under no load, the Peltier element can produce a temperature differential of up to $40 \mathrm{~K}$, but in practice the measurable dewpoint depression is somewhat smaller, and hence the Snow White does not operate in the stratosphere (Vömel et al. 2003). Because of the limited available cooling capacity, the mirror may also lose its frost layer in very dry tropospheric layers $(\mathrm{RH} \leq 5 \%)$. The dewpoint temperature measurement accuracy has been determined by the manufacturer to be $\pm 0.2^{\circ} \mathrm{C}$ ( $\sim \pm 2 \%$ of the RH percent value). The performance, and its limitations, are described in more detail in Fujiwara et al. (2003), Vömel et al. (2003), Vaughan et al. (2005), and Miloshevich et al. (2006).

The NOAA-FPH has been described in detail by Vömel et al. (2003). The instrument allows measurements under stratospheric conditions, even with frostpoint depressions exceeding $100 \mathrm{~K}$. The measurement accuracy of the NOAA-FPH is mainly dependent on the instrument controller's ability to maintain a steady dew/frost layer. The accuracy is typically better than $0.5^{\circ} \mathrm{C}$ in frost-point temperature (Vömel et al. 1995), which translates to $6 \%$ of RH in the LT and less than $10 \%$ of RH in the UT and the stratosphere. The vertical resolution is mostly determined by the response time of the instrument, which is better than $10 \mathrm{~s}$ in the troposphere and better than a few tens of seconds in the stratosphere. The CU-CFH is a more modern approach to a cryogenic frost-point measurement by the University of Colorado (Vömel et al. 2007a). Both the NOAAFPH and CU-CFH use a Vaisala RS80 as a telemetry unit (during LAUTLOS it was the RS80-H). During LAUTLOS, four test flights were made with the CU$\mathrm{CFH}$. The tropospheric data of these flights were included in the statistics with the NOAA-FPH in this study. These two latter FPHs are regarded as reference instruments in this tropospheric comparison.

Two difficulties common to all FPH measurements are that the mirror temperature has to be controlled very precisely and the liquid-to-ice phase change of the 
deposit on the mirror has to be determined clearly; otherwise, there is a water/ice ambiguity. The effects of the latter are seen as strong bias errors in the temperature range where the phase change takes place.

The FLASH-B was developed at the Central Aerological Observatory in Russia (Yushkov et al. 1998, 2000). The instrument uses the photodissociation of $\mathrm{H}_{2} \mathrm{O}$ molecules at the Lyman- $\alpha$ frequency followed by measurement of the fluorescence of the excited $\mathrm{OH}$. The Lyman- $\alpha$ source of vacuum ultraviolet (VUV) light $(121.6 \mathrm{~nm})$ is a hydrogen discharge lamp. The detector of $\mathrm{OH}$ fluorescence at $308-316 \mathrm{~nm}$ is a photomultiplier run in photon-counting mode. Under stratospheric conditions with negligible $\mathrm{O}_{2}$ absorption, the intensity of the fluorescent light is directly proportional to the $\mathrm{H}_{2} \mathrm{O}$ mixing ratio. In the troposphere, $\mathrm{O}_{2}$ absorption is not negligible, and hence there is an expected dry bias in a humid atmosphere below the $300-\mathrm{hPa}$ level.

The operational range of the FLASH-B is from 300 to $7 \mathrm{hPa}$ (i.e., $8-35 \mathrm{~km}$ ) in altitude and $-95^{\circ}$ to $+40^{\circ} \mathrm{C}$ in temperature. According to the manufacturer, the measurement range for FLASH-B is from 0.5 to 100 ppmv $\mathrm{H}_{2} \mathrm{O}$. The estimated total uncertainty of the instrument is then $9 \%$ or 0.5 ppmv under stratospheric conditions.

\section{Correction of the Humicap RH}

The discovery of the dry bias in RS80 RH measurements prompted the development of several correction approaches. In this study, the two of them have been applied. They are those developed in National Center for Atmospheric Research (NCAR)/Vaisala cooperation (Miloshevich et al. 2001, 2002) and by the German Weather Service (DWD) observatory at Lindenberg (Leiterer et al. 2000). Both methods include an additional/improved temperature dependence correction (TDC) and time lag corrections (TLCs). In the subsequent text the former is referred to simply as the Miloshevich correction and the latter as the "Method of Lindenberg" (MOL). The impacts of these corrections on RS80 RH data are described in the following.

The version of the Miloshevich TDC used here is based on the comparison with the NOAA-FPH and laboratory measurements at Vaisala. The Miloshevich TDC is described in detail in Miloshevich et al. (2001) and Wang et al. (2002). The MOL correction scheme is described in Leiterer et al. (2000, 2005). MOL is not available for the RS80-H. In addition to the TD error, MOL also addresses the RH-dependent part of the RS80-A error, which is a factor in temperatures above $-40^{\circ} \mathrm{C}$. In the MOL this is provided by a modeled ground check correction at $100 \% \mathrm{RH}$ (GC in plots).
This should not be confused with the standard Vaisala ground check at $0 \% \mathrm{RH}$. For this comparison, the value of $+7.5 \% \mathrm{RH}$ is applied for the MOL ground check on the basis of local tests and the results of Leiterer et al. (2005).

The resulting correction factors for the abovementioned TDCs are shown in Fig. 1 at various humidities as a function of temperature. Here the difference in magnitude of the RS80-A and - $\mathrm{H}$ corrections is obvious (please note the difference in scaling). There is also an observable difference between the Miloshevich approach and MOL for RS80-A, the former having a very strong increase in magnitude for $T<-50^{\circ} \mathrm{C}$ and $\mathrm{RH}>$ $30 \%$, while the latter is more effective for $T>-30^{\circ} \mathrm{C}$ due to the ground check part of the correction.

In addition to the TD bias errors, there are also observable time lag errors in radiosondes. The latter tends to smooth out sudden changes in ambient $\mathrm{RH}$ profiles in the upper troposphere. In this study, the effects of the sensor time lag are taken into account by applying the Miloshevich TLC (Miloshevich et al. 2004) for the RS80-A, RS80-H, RS90, and RS92. The MOL version of TLC is only available for the RS80-A (Leiterer et al. 2005).

As a general comment, the original data, with a $1 \%$ $\mathrm{RH}$ reading interval, are not suitable for TLC algorithms. The RH profile must therefore be smoothed. In addition, TLC procedures need high-resolution data (i.e., a 10-s interval at most). This presents a problem when using WMO standard- and significant-level data. TDC algorithms do not have any of these restrictions.

Effects of the Miloshevich and MOL correction schemes are demonstrated in Fig. 2 with the help of a LAUTLOS comparison night flight on 24 February 2004. In this case, the temperature at the surface was approximately $-20^{\circ} \mathrm{C}$ and at the tropopause level $-60^{\circ} \mathrm{C}$. Regarding the atmospheric humidity conditions, the LT was dry, but the midtroposphere (MT) and UT were ice supersaturated.

In Fig. 2, the available TDCs are applied to RS80 profiles along with the Miloshevich TLC, which is applied for all Vaisala radiosondes. It is observed that the magnitude of the TLC is significant only for the RS80$\mathrm{H}$, which is considerably slower in the UT compared to the others. However, its TDC is much smaller than that for the RS80-A. The RS80-A obviously suffers from a large dry bias in the humid UT (and therefore a larger TDC). It was noticed that the TLC parts of both correction schemes for the RS80-A do in fact produce very similar results, and that the differences arise mainly from the TDC part. For the sake of clarity, the effect of the MOL TLC alone is therefore not shown in the plot. 

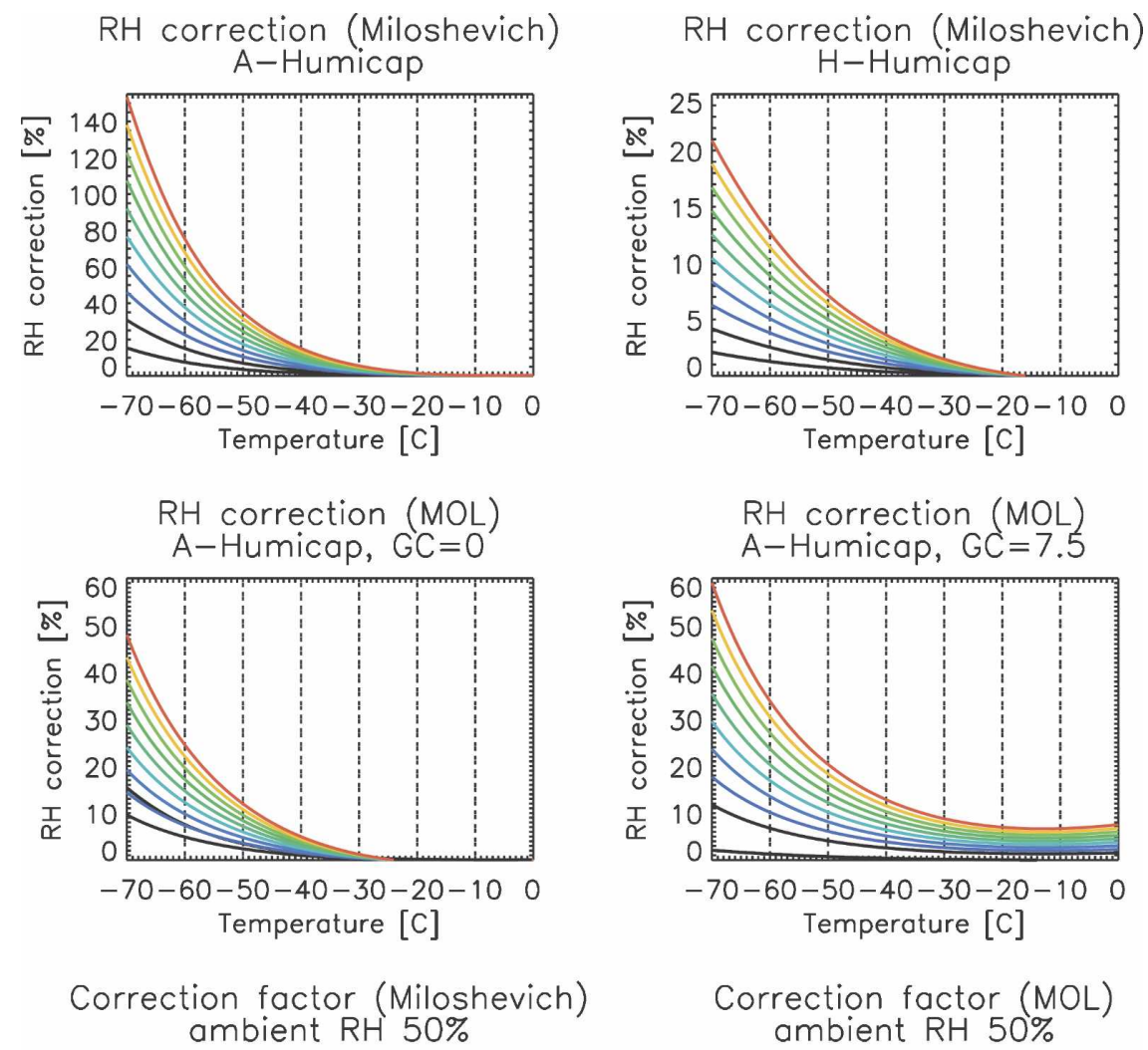
ambient $\mathrm{RH} 50 \%$
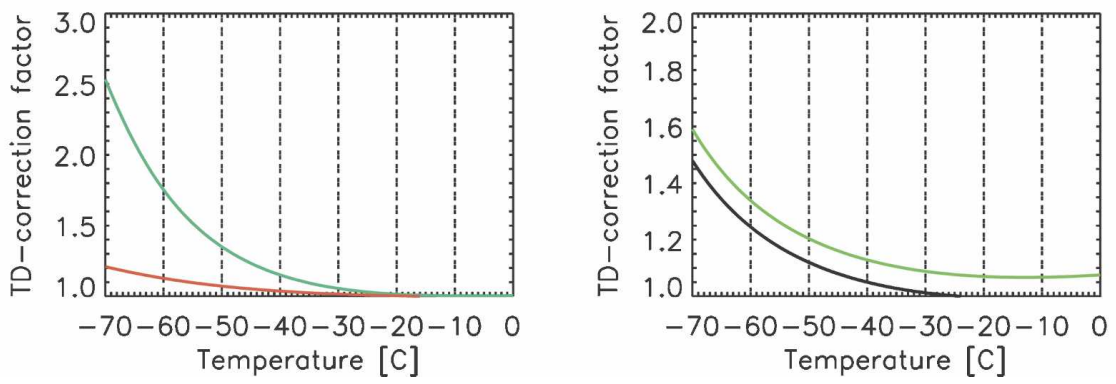

FIG. 1. (top) The size of the Miloshevich TD correction at various RHs as a function of $T$ for the A- and H- Humicaps. (center) The size of the MOL correction for the A-Humicap with and without the MOL ground check. The correction is of the form $\mathrm{RH}_{\text {corrected }}=\mathrm{TD}$ correction $+\mathrm{RH}_{\text {measured }}$. The $\mathrm{RH}$ interval between the $\mathrm{RH}$ correction curves is $10 \% \mathrm{RH}$, the red being equal to $100 \% \mathrm{RH}$. (bottom) The magnitude of the correction factors at $50 \% \mathrm{RH}$. Colors in bottom panels denote A-Humicap (green), H-Humicap (red), and MOL without MOL ground check (black). Please note the effect of the different $y$ scales in the plots.

In this example, the Miloshevich TDC does not make any adjustment to the RS80-A RH below an altitude of $5 \mathrm{~km}$. Here, the effect of the MOL ground check part of the correction is seen below $1 \mathrm{~km}$, where the ambient $\mathrm{RH}$ is high. The smoothed data are shown too, to demonstrate that their difference from the original (i.e., raw data) is almost invisible.

Unfortunately, the TLC for the FN was not available at the time of this comparison study. Because of this, the FN disagrees with the others in the following examples, especially in the UT. The development of a
TLC for the FN is therefore recommended. It would be comparable to that for the RS90 (see section 5b). Profile comparisons hereafter are based on the fully corrected data, unless otherwise mentioned.

\section{LAUTLOS experiment and data}

In February 2004, northern Finland was influenced by frequent low pressure activity, and tropospheric clouds were abundant. The tropopause altitude varied around $9 \mathrm{~km}$, with tropospheric temperatures generally 

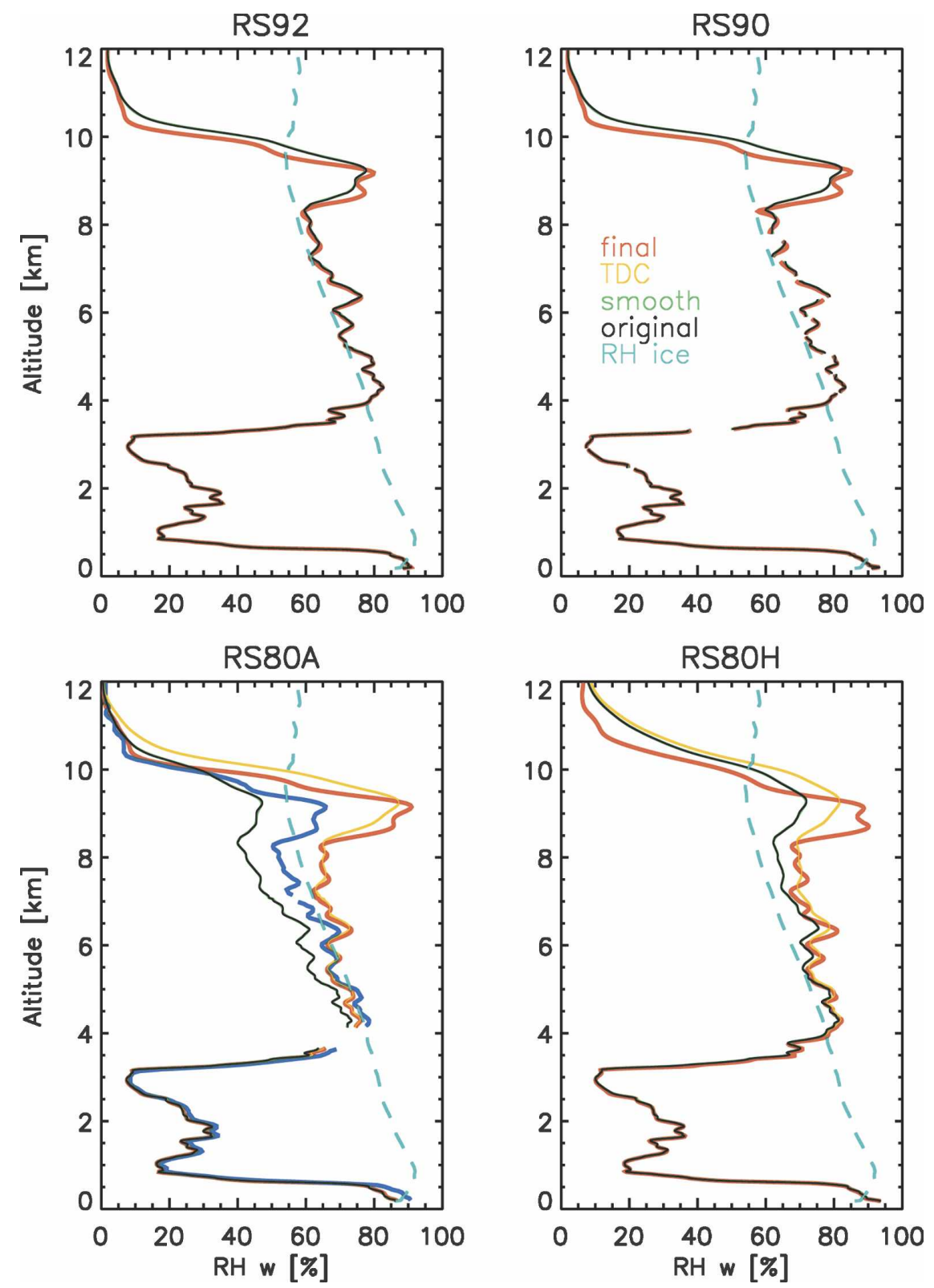

FIG. 2. The corrections applied to an example RH profile on $24 \mathrm{Feb} 2004$. The original raw data are shown in black. The Miloshevich corrections are as follows: final, that is, fully corrected, data (thick red), bias correction TDC (orange), and smoothed data (green). Final data include TLC for all instruments, in addition to which, TDC is applied to both types of RS80. In the case of the RS80-A, the MOL correction, including both TLC and TDC, is shown too (thick blue). As a reference, $\mathrm{RH}$ with respect to water at ice saturation is shown by dashed turquoise line.

lying between $-65^{\circ}$ and $+5^{\circ} \mathrm{C}$. On average, the surface temperature was approximately $-5^{\circ} \mathrm{C}$ at the time of a sounding. A set of atmospheric temperature profiles is shown in Fig. 3 to describe the atmospheric temperature structure in more detail. In these high-latitude winter conditions, with a low solar elevation, the radiation effects for sensors are smaller as compared to low- latitude conditions (cf. earlier-reported intercomparisons). Because of these conditions, cloud effects had an additional importance during LAUTLOS.

During LAUTLOS we used two different measurement payload configurations. The one including heavy FPHs (hereafter the "heavy payload") consisted of a NOAA-FPH or CU-CFH, a FLASH-B, an RS92, an 


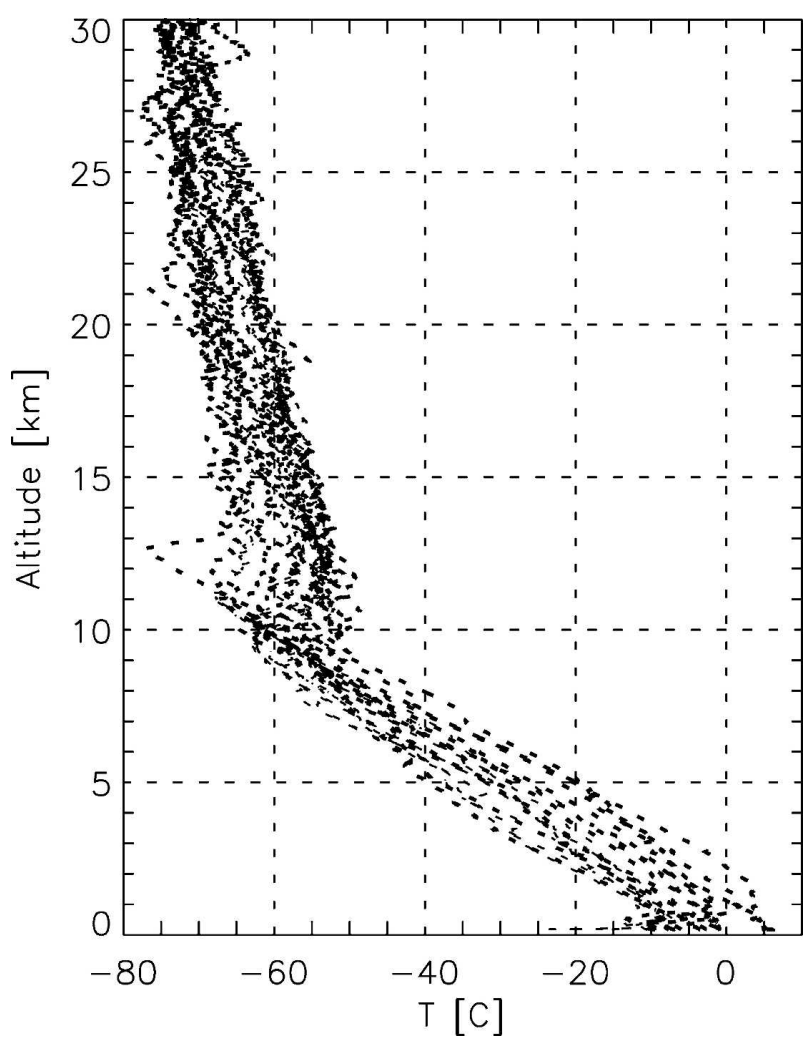

FIG. 3. Atmospheric temperature profiles during LAUTLOS.

RS80-A (as a telemetry unit for the FLASH-B), an RS80-H (as a telemetry unit for the NOAA-FPH or CU-CFH), and optionally a Snow White. For lifting this type of payload we used $19000 \mathrm{ft}^{3}$ plastic balloons that reached an altitude of $\sim 25 \mathrm{~km}$. The other configuration, the "light payload," was flown without the heavy FPHs and FLASH-B, which meant that we were able to fly it during sunlit hours, too. It comprised a Snow White hygrometer and RS92, RS90, FN, and RS80-A radiosondes. For flying this payload we used TOTEX rubber balloons, providing burst altitudes of over 30 $\mathrm{km}$. The majority of comparison flights carried light payloads. In both configurations the instruments were mounted on a horizontal, cross-shaped rig, to be able to sample exactly the same air mass. The number of measurements, including the division into day and night measurements, is shown in Table 2.

The comparison data are available on the Finnish
Meteorological Institute's Arctic Research Centre (FMI-ARC) data server (see http://fmiarc.fmi.fi/ LAUTLOS_web/index_lautlos.html). They are stored on a common time grid with a 2-s time resolution (synchronization error $<4 \mathrm{~s}$ ). The approximations for saturation water vapor pressure $(e)$ applied are based on Hyland and Wexler (1983). Comparisons between the different approximations for $e$ are available from the University of Colorado (see http://cires.colorado.edu/ $\sim$ voemel/vp.html) and in Leiterer et al. (1997).

\section{Results and discussion}

This section discusses the key findings of the tropospheric comparisons. The objective is to show the temperature dependence of the various radiosonde types (RS80-A/H, RS90, RS92, and FN) and to test the performance of the available correction algorithms for them. This is done with the help of reference measurements made with NOAA-FPH, CU-CFH, and Snow White. In these tropospheric comparisons, the NOAAFPH and CU-CFH can be considered as the best known and least affected by clouds (see section 2c). Along with the statistics, the most important characteristics of these instruments are pointed out with the help of some representative examples.

The statistical analyses, which are presented in Figs. 4 and 5, have been compiled to show the typical $T$ - and $\mathrm{RH}$-dependent behavior of the radiosondes. Instead of calculating average differences for separate temperature bins representing the LT, MT, and UT environments, these relations are demonstrated qualitatively by showing the RH differences in both $T-\mathrm{RH}$ and RH- $Z$ spaces (Figs. 4 and 5) and by using the ambient $\mathrm{RH}$ as a third dimension (represented by a color). The reason for this is that too few ascents were available for binning the data and still having robust statistics. The values shown in Fig. 4 are absolute RH differences (\% $\mathrm{RH}$ ), while in Fig. 5 they are relative (\%). Apart from the $T$-RH space comparisons in Fig. 4, Fig. 5 shows the relative differences between the sondes as a function of height. It is seen that the relative differences are larger in the UT (Fig. 5), compared to the absolute differences in Fig. 4; this is because the ambient RH has a very small value in the UT compared to the radiosonde

TABLE 2. The inventory of LAUTLOS balloon flights.

\begin{tabular}{lccccccccc}
\hline \hline Instrument & NOAA-FPH & CU-CFH & FLASH-B & Snow White & FN & RS92 & RS90 & RS80-A & RS80-H \\
\hline Total & 10 & 4 & 13 & 29 & 29 & 27 & 18 & 19 & 10 \\
Day & - & - & - & 14 & 14 & 10 & 13 & 14 & - \\
Night & 10 & 4 & 13 & 15 & 15 & 17 & 5 & 5 & 10 \\
\hline
\end{tabular}



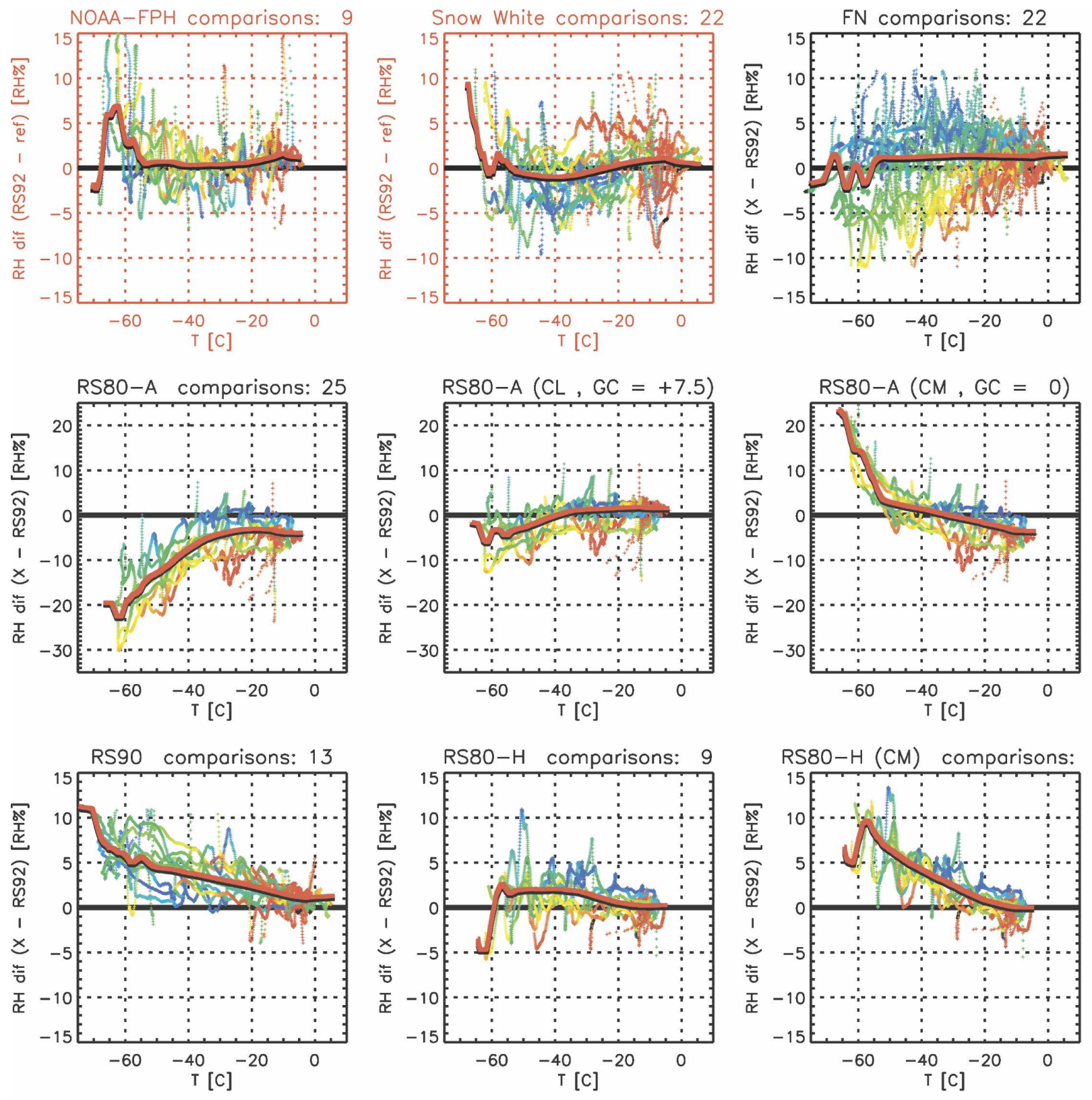

9

$\mathrm{RH}[\%]$

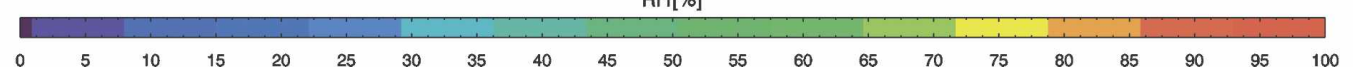

FIG. 4. Radiosonde comparisons of RS80-A and -H, RS90, and FN (against the RS92). The plot shows RH differences against temperature. The ambient RH (from the RS92) is shown by the color scale. CL denotes the MOL correction, and CM the Miloshevich TD correction for the RS80. The red line with a black shadow shows the averaged difference. Reference comparisons of RS92 against NOAA-FPH and CU-CFH and Snow White are plotted with a red axis in the two first windows.

reading interval and accuracy. Reference comparisons with FPHs are distinguished from radiosonde comparisons with red plot axes for clarity.

Comparisons are based on the ascent data so as to be able to include radiosondes and to obtain a full profile from the surface up to the tropopause. For strato- spheric comparisons this would involve the risk of having the measurements contaminated by the balloon or instrument outgassing. In the troposphere these factors are generally very small compared to the sensor differences. The FLASH-B and the day version of the Snow White form an exception to this, as they suffered from 

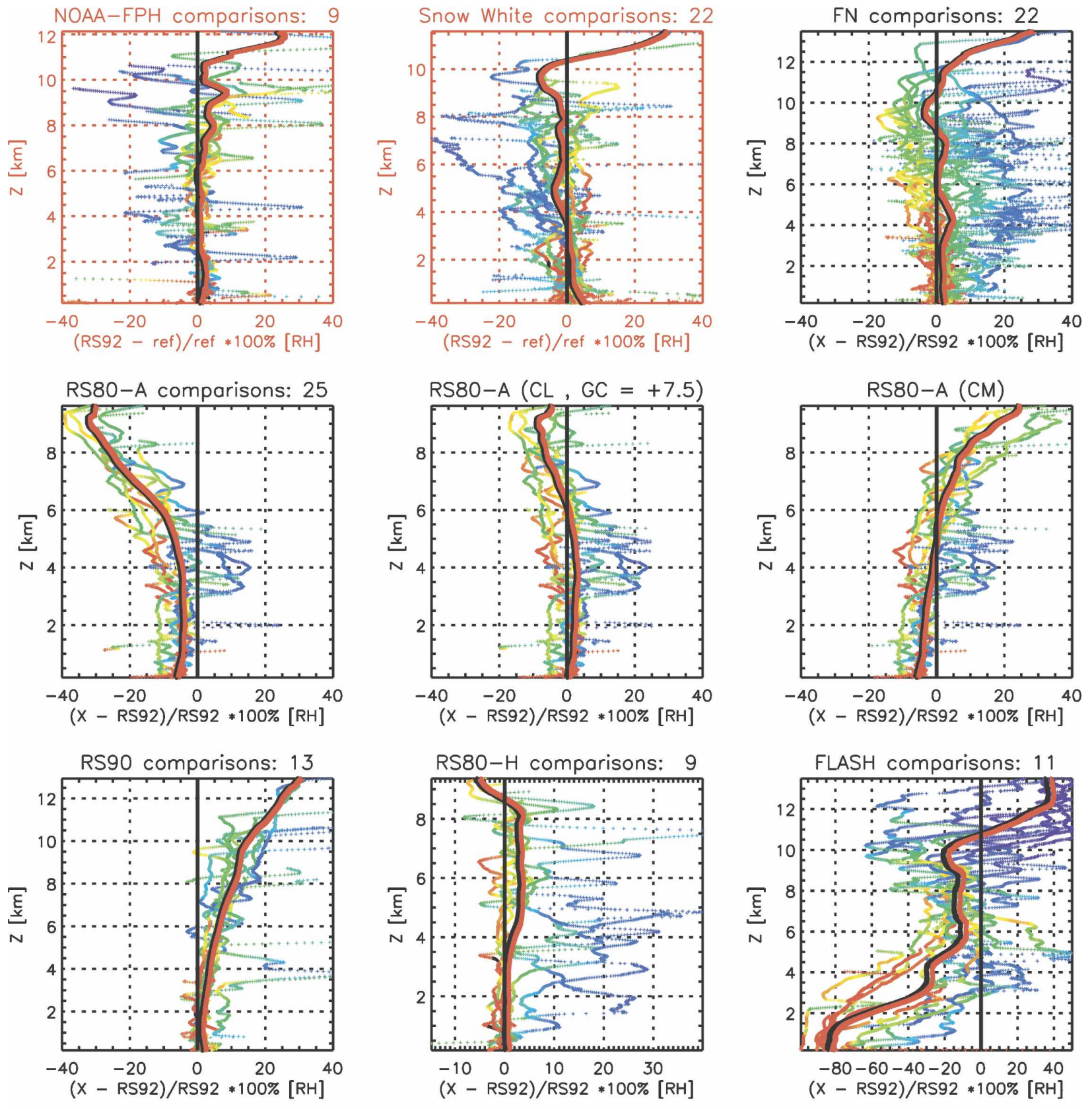

$\mathrm{RH}[\%]$

FIG. 5. Radiosonde comparisons of RS80-A and -H, RS90, FN, and FLASH-B (against the RS92). The plot shows the percentile difference in RH as a function of altitude. The plot key is as in Fig. 4.

self-contamination during ascents. For this reason, they are not used as references in the UT comparisons.

The presented statistical analysis does not include the TLC for radiosondes. The decision to omit the TLC is based on two considerations: 1) the main audience for this work, that is, people who utilize radiosonde databases, seldom has access to the high-resolution data that the TLC requires; and 2) the maximization of the data density in the UT. The effect of having a TLC was studied, and it was found that the time lag-corrected average differences did not differ much from those without it (not shown here). However, the effect of a time lag is assumed to be greater where the tropopause is situated higher, that is, at low latitudes. Time lag- 
related features are demonstrated with example profiles that are discussed along with the statistical analysis. These include the TLC.

\section{a. Reference comparisons with FPHs}

Before proceeding with the radiosonde comparison, the RS92 is compared with the following reference instruments: the NOAA-FPH, CU-CFH, and Snow White. The NOAA-FPH and CU-CFH flights were performed at night, which provides better operating conditions for all of the instruments (i.e., no radiation effects). There were 14 flights of this type altogether. The results of this comparison were used for selecting the working reference for the radiosonde comparison, that is, the 29 light payload flights (see section 4).

Two example profiles are referenced throughout the discussion: the first (Fig. 6) describes the performance of the sensors in an ice-supersaturated UT and a dry

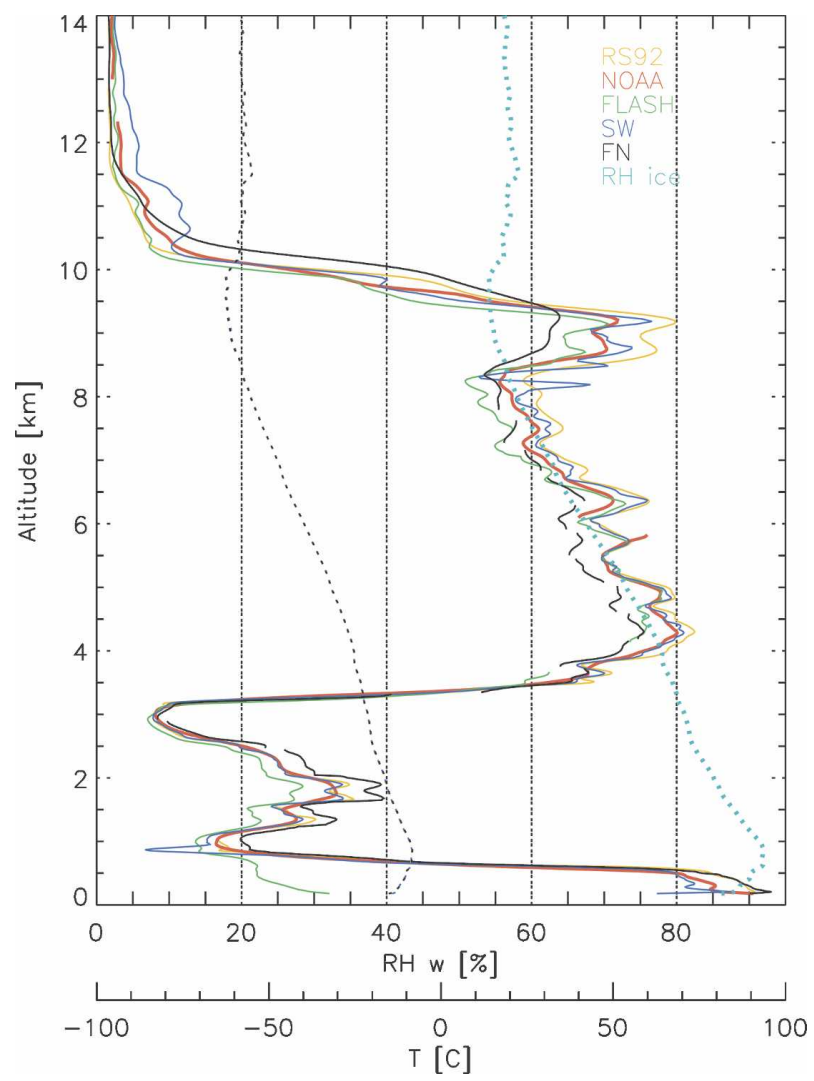

FIG. 6. Example of reference class instrument performance in the troposphere inside a thick cloud. The plotted parameter is relative humidity (RH\%). Sondes: NOAA-FPH (thick red), time lag-corrected RS92 (orange), Snow White (blue), and FN (black). The RH with respect to water at ice saturation is shown in turquoise. For RH profiles, a 10-s-wide (i.e., $50 \mathrm{~m}$ ) smoothing operator is applied to make visual inspection easier. The left-hand side profile shows ambient temperature (broken line).
LT, whereas the second example (Fig. 7) shows their performance in a dry UT. Of these, the former was used in Fig. 2 to demonstrate the efficiency of the various time lag corrections. In all of the presented examples, the Miloshevich TLC has been applied for the Vaisala instruments (but not for the FN). As a result, the FN appears to have a time lag compared to the others. The RS80-A has been corrected using both the Miloshevich and MOL correction schemes (both including TDC and TLC). The statistical comparisons presented do not include time lag corrections.

The RS92/NOAA-FPH and CU-CFH comparison in Fig. 4 shows good agreement below the UT, where the differences generally lie between $\pm 5 \% \mathrm{RH}$. Actually, in the $T$ interval from -20 to $-55^{\circ} \mathrm{C}$ there is no bias at all. In the UT $\left(T<-55^{\circ} \mathrm{C}\right)$, the RS92 seems to have a wet bias of $\sim 5 \%$ RH. Figure 5 supports this by showing that the relative difference generally varies between $\pm 5 \%$ in the LT and $\pm 10 \%$ in the MT and UT.

The UT wet bias of the RS92 is situated just below the tropopause. It may be thought that this is due to the slower response time of the RS92 compared to the faster optical instruments. The effect of the slower re-

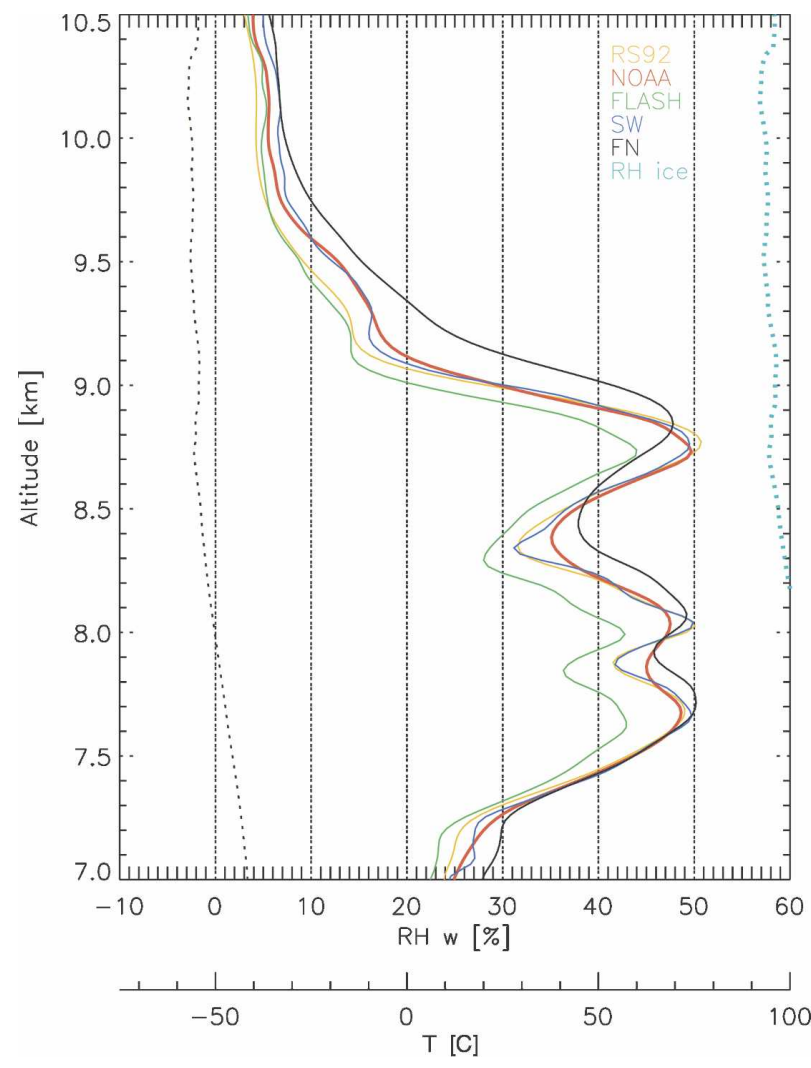

FIG. 7. Example of the reference class instrument performance in the troposphere in an ice-subsaturated UT. The plot key is as in Fig. 6. 
sponse time of the RS92 is clearly seen in Fig. 2. As the example in Fig. 7 uses the TLC for the RS92, one can observe that the time lag error has almost disappeared. However, it was found in the statistical comparison that with the TLC applied, the UT wet bias for the TS92 was reduced by a half (not shown here). This suggests that the UT wet bias in the RS92 is not just a time lag issue, but is additionally related to the termination of the heating cycle at $-40^{\circ} \mathrm{C}$ (Nash et al. 2005; Vömel et al. 2007b).

The LT differences, at $T>-20^{\circ} \mathrm{C}$, are mostly caused by the water/ice ambiguity that is a characteristic of FPHs. The difference spikes originate mainly from the slower time response of the Humicap and from the noise generated by the gain change episodes of the NOAA-FPH instrument. The most visible effects of the gain change episodes have been removed from the data. The observed agreement in this statistical comparison partly results from the fact that these comparisons are based on nighttime data; radiation effects do not therefore play a role here. With daytime data some dry bias in the UT would be expected for the RS92 (Vömel et al. 2007b). However, the following Snow White/RS92 comparison suggests that radiation effects were small during LAUTLOS.

As the night version of the Snow White enjoys a very good agreement with the NOAA-FPH (Fig. 6) and is even faster (Fig. 7), it could be considered as the reference for the radiosonde comparison. Unfortunately, flights with the daytime version of the Snow White suffered frequently from ice contamination in the moist UT. The contaminated data are rejected from the statistical Snow White/RS92 comparison, leading to it being slightly biased toward dry UT and night conditions. The remaining daytime data, which are included in Fig. 4 , suggest that the RS92 radiation dry bias is not an issue during the LAUTLOS anyway (see section 4). According to Fig. 4, the RS92 agrees closely with the Snow White. It seems that there is virtually no bias in the LT and MT, but the RS92 has some $1 \%$ or $2 \% \mathrm{RH}$ dry bias in the moist UT. According to the day/night comparisons between the various profiles, like the one in Fig. 8, this small difference in the UT is not a signature for the RS92 radiation dry bias. Inspection of individual sounding profiles suggests that the RS92 is $\sim 5 \% \mathrm{RH}$ drier in slightly subsaturated conditions than the Snow White, but may have a similar wet bias in clearly supersaturated conditions in the UT as in Fig. 6. Figures 4 and 5 also indicate that the RS92 has a strong dry bias just below the tropopause. This bias is removed totally if the TLC is applied to the RS92 data, telling us that its source is in the slower time response of the RS92. Time lag-corrected profiles are seen in Figs. 7

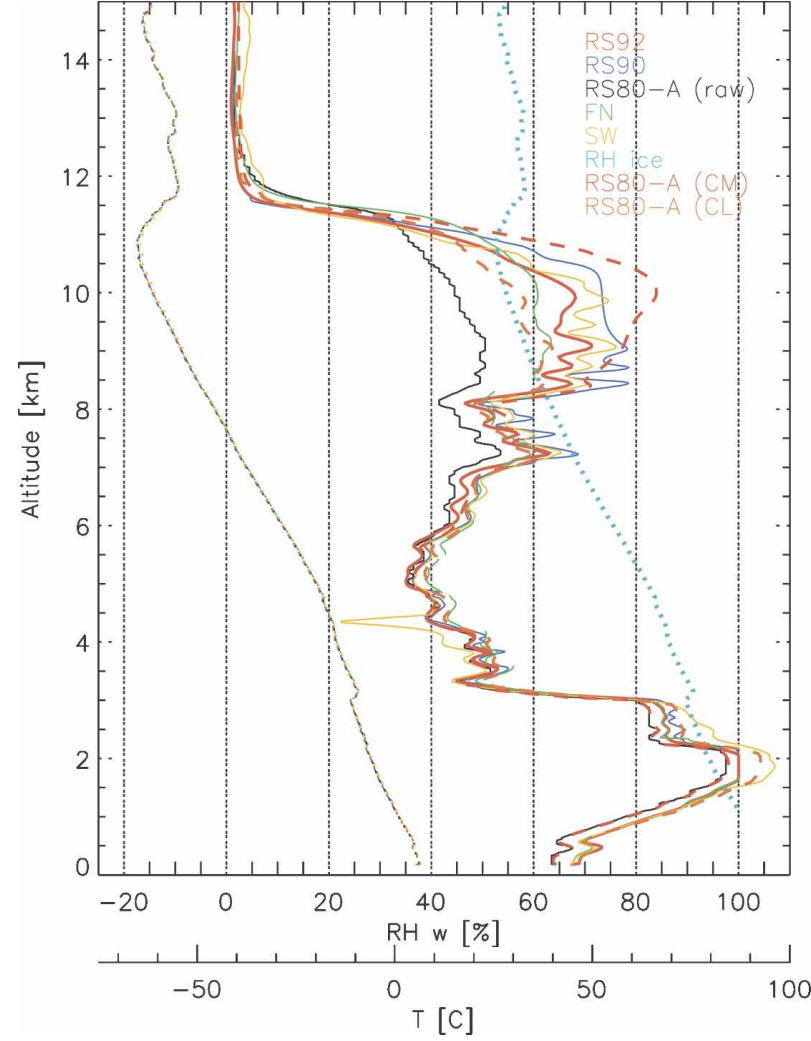

FIG. 8. Cirrus case from the LAUTLOS material. The line colors are as follows: RS92 (thick red), RS90 (blue), FN (green), and Snow White (yellow). The uncorrected RS80-A is drawn in black (raw data). Corrected RS80-A profiles are drawn with dashed lines as follows: with the MOL correction (orange), and with the Miloshevich correction (red). The left-hand side set of profiles shows ambient temperature (broken lines). Otherwise, same as in Fig. 6.

and 6. These observations are in line with Miloshevich et al. (2006) and Vaughan et al. (2005).

If cloud contamination is not considered, the remaining erroneous anomalies in Snow White data are related mostly to traces of the water/ice ambiguity or difficulties in maintaining the frost/mist layer on the mirror surface, which usually happens in a very dry environment. The former problem is usually observed as anomalous data in ambient temperatures above $-30^{\circ} \mathrm{C}$. Anomalies related to these issues are seen in Snow White data in Fig. 6 at an altitude of $1 \mathrm{~km}$ and in Fig. 8 at $4.5 \mathrm{~km}$. These anomalies have been screened out of the comparison data, but some traces of them still remain in Figs. 4 and 5, introducing some additional noise in the LT.

The agreement between the NOAA-FPH, Snow White, and RS92 (and FN) applies only in the troposphere. In the stratosphere, the radiosondes mentioned would have a dry bias of more than $50 \%$ (i.e., a couple 
of ppmv or $0.5 \%$ to $1.5 \% \mathrm{RH})$. The Snow White seemed to lose its sensitivity to atmospheric water vapor completely in the stratosphere, where only the NOAA-FPH and FLASH-B seem to agree well. According to Yushkov et al. (2005) and Vömel et al. (2007c), the FLASH-B is a precise stratospheric instrument, but its measurements degrade below $7 \mathrm{~km}(\sim 300$ $\mathrm{hPa}$ ) due to the increased $\mathrm{O}_{2}$ absorption there (see Fig. $5)$. In the case of FLASH-B, descent data are preferable.

Because the NOAA-FPH was flown only at night, and the day version of the Snow White performed poorly in the UT, the need for a working reference arose for the radiosonde comparison. The RS92 was chosen for this purpose on the basis of the reference comparisons. In using a radiosonde as a reference, the role of solar radiation effects had to studied. This was tested in a Snow White/RS92 comparison that included both night- and daytime data; this comparison suggested that radiation effects were not an issue during LAUTLOS.

\section{b. Radiosonde comparisons}

The radiosonde comparison included the FN, RS90, and $\mathrm{RS} 80-\mathrm{A}$ and $-\mathrm{H}$, using as a working reference the RS92. The results of the comparison are described in the following subsections and in Figs. 4 and 5. Figure 8 presents an example that helps to show the characteristic differences between the Vaisala radiosonde generations and Snow White in a supersaturated UT and LT. The example is a nighttime flight, that is, no solar radiation error. The example presents penetration of a cloud layer situated between 8 and $11 \mathrm{~km}$; the ambient temperature at cloud base is about $-50^{\circ} \mathrm{C}$ and at cloud top is $-65^{\circ} \mathrm{C}$. In the case of the LT cloud, between 1.5 and $2.5 \mathrm{~km}$, the ambient temperature is above $-5^{\circ} \mathrm{C}$. It is seen that the features discussed in connection with the statistical analysis are well displayed in this representative example. The example case in Fig. 9 is to give an impression of the performances of the corrected RS80-A and -H. Please note that the TLC is applied to the Vaisala instruments in all of the presented examples.

\section{1) $\mathrm{FN} / \mathrm{RS} 92$}

The FN has the best agreement with the RS92, having no visible bias on average, but they do disagree in certain conditions. In general, the size of the disagreement is mainly dependent on temperature, while its sign depends on the distance from the ice-saturated $\mathrm{RH}$ value. More precisely, for $T<-30^{\circ} \mathrm{C}$ and in high hu-

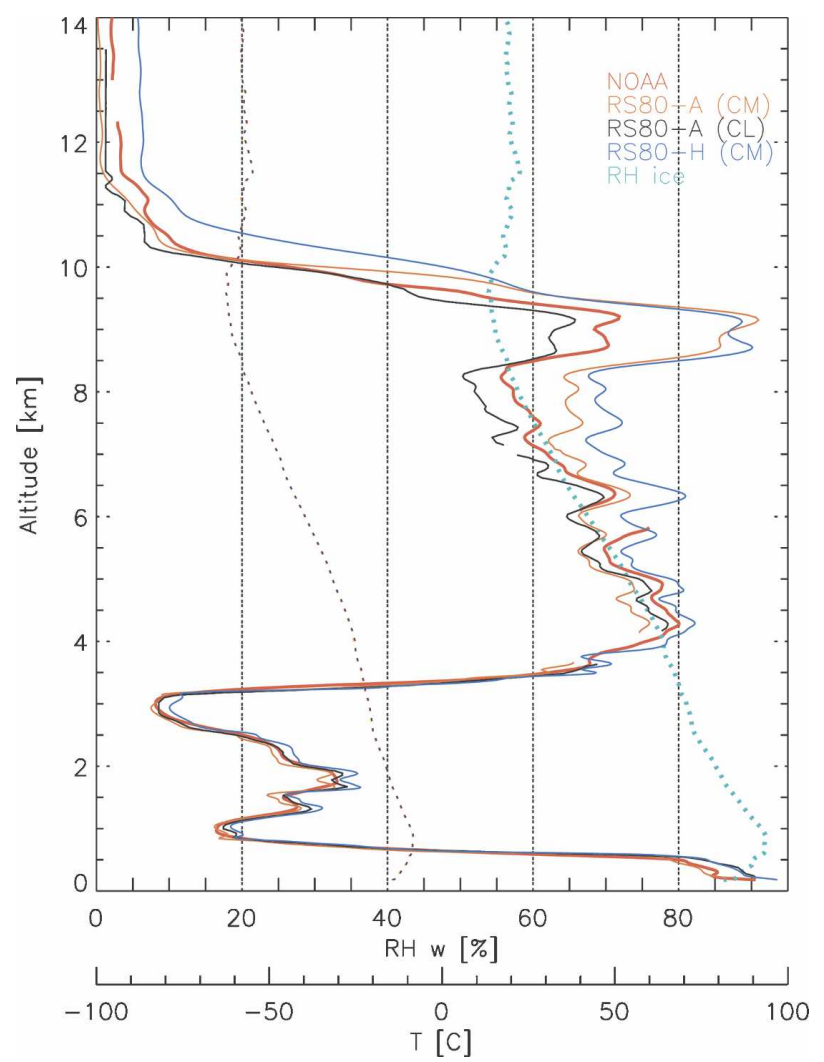

FIG. 9. Example of RS80 performance in the troposphere inside a thick cloud. The plotted parameter is relative humidity (RH\%). Sondes: NOAA-FPH (thick red), RS80-A with MOL correction (black), RS80-A with Miloshevich correction (orange), and RS80-H with Miloshevich correction (blue). Otherwise, same as in Fig. 7.

midity (70\% to $50 \% \mathrm{RH})$, FN shows a $2 \%-6 \%$ lower $\mathrm{RH}$ than the RS92. But for $T<-30^{\circ} \mathrm{C}$ and in lower humidities ( $40 \%$ to $20 \% \mathrm{RH})$ the $\mathrm{FN}$ gives a $2 \%-4 \%$ higher RH than the RS92. The maximum differences, $\sim 10 \% \mathrm{RH}$, occur at $T \approx-60^{\circ} \mathrm{C}$. Figure 5 supports these findings by showing that the bias is less dependent on altitude than on the ambient $\mathrm{RH}$. The relative differences indicating a wet bias in extremely dry layers may seem to be large, but in RH units they translate to a few percent RH (see Fig. 4).

At the time of writing this paper, the TLC was not available for the FN. The time lag effect is seen most clearly as a wet bias above humid layers in the UT in Figs. 6 and 7.

According to Fig. 6, the FN seems to agree rather well with the NOAA-FPH, but shows the same characteristic differences as in the comparison with the RS92, thus revealing the superiority of the RS92. This conclusion is supported by the fact that the FN can still be considered to be in the development phase. 


\section{2) $\mathrm{RS} 90 / \mathrm{RS} 92$}

The RS90 has a positive bias compared to the RS92 for $T<-10^{\circ} \mathrm{C}$. In Fig. 4 it is seen that the difference vanishes when $T$ is close to $0^{\circ} \mathrm{C}$; the RS90 wet bias thus seems to increase semilinearly with decreasing temperature. The bias is larger at high $\mathrm{RH}$, increasing then from $\sim 0 \% \mathrm{RH}$ at $0^{\circ} \mathrm{C}$ to $10 \% \mathrm{RH}$ at $-60^{\circ} \mathrm{C}$, while being considerably less in a low ambient RH environment. This is confirmed in Fig. 5, where the good agreement with the RS92 is evident below an altitude of 4 $\mathrm{km}$. The relative differences also suggest that the error is not very $\mathrm{RH}$ dependent.

\section{3) $\mathrm{RS} 80-\mathrm{A} / \mathrm{RS} 92$}

The general impression gained in this comparison is that the RS80-A has a dry bias throughout the troposphere. The largest underestimate takes place at low temperatures $\left(-40^{\circ}\right.$ to $-70^{\circ} \mathrm{C}$ ) and in high $\mathrm{RH}$ (close to ice saturation). On average, the dry bias is $5 \% \mathrm{RH}$ in the LT for $T>-30^{\circ} \mathrm{C}$. In a saturated UT, the RS80-A RH underestimate increases considerably, being even as high as $30 \%$ RH. A bias of this size must be taken into account when doing climatological analysis or when assimilating radiosonde data. From Fig. 5, it is evident how the difference (now relative) increases quickly with altitude. In the LT the difference is about $5 \%$, while in the UT it is $\sim 30 \%$. Positive anomalies (in dry layers above clouds) are related to the slower response time of the RS80. When correcting RS80 data one has to be careful not to amplify these erroneous features. Profiles affected by sensor icing have been removed from these comparisons. Unfortunately, this reduction in the number of valid profiles removes the possibility of day-night comparisons. The majority of the analyzed cases can be considered as night soundings.

It is seen that the corrected RS80-A data better agree with the RS92 than the uncorrected. When the RS80-A RH was corrected with the TDC algorithm developed by Leiterer et al. (2000), the dry bias was reduced significantly at all altitudes. Figure 4 shows that for $T>$ $-30^{\circ} \mathrm{C}$ (i.e., in the LT and MT) the averaged dry bias in the RS80-A RH has vanished. This improvement results from the modeled ground check correction, which is included in the MOL correction algorithm. The MOL ground check correction is designed to address the RHdependent portion of the Vaisala calibration. For $T<$ $-30^{\circ} \mathrm{C}$ and at high $\mathrm{RH}$ values (i.e., where the TD error is large) the bias has diminished considerably; a $\sim 5 \%$ RH dry bias still remains in the UT. The remaining maximum dry bias values have been reduced to $<15 \%$
RH. However, looking at the average, the temperature dependence seems to have been almost fully removed. In Fig. 8, the correction agrees very well with the FN, which is not a surprise, since the FN method measurements are the basis for the correction algorithm.

The TDC part of the Miloshevich correction for the RS80-A is effective while $T \ll-30^{\circ} \mathrm{C}$. In that region the correction is stronger than the MOL correction, and results in removing the dry bias totally in the UT, even overcorrecting with $T<-50^{\circ} \mathrm{C}$ and a high $\mathrm{RH}$ (i.e., in the UT conditions typical in LAUTLOS). However, at temperatures characteristic of the LT, this correction does not have any effect on the RS80-A dry bias. The overcorrection may be explained by the statistics that are used for calculating the MOL, which are closer to conditions during the LAUTLOS, and by the possibility that the RS80-A radiation dry bias plays a bigger role in the comparisons that are behind the Miloshevich correction. These hypotheses are not tested.

\section{4) $\mathrm{RS} 80-\mathrm{H} / \mathrm{RS} 92$}

According to this comparison, it is quite evident that the RS80-H does not suffer from dry bias in saturated conditions nearly as much as the RS80-A does. This difference is an important fact that should be taken into account when using RS80 $\mathrm{RH}$ records for assimilation or for trend calculations. In the UT, in a saturated environment, the maximum dry bias for the uncorrected RS80-H is $\sim 5 \%$ RH (red anomalies in Figs. 4 and 5). However, the uncorrected RS80-H seems to experience a small wet bias $(\sim 2 \% \mathrm{RH})$ on average; this is partly a result of the slowness of the RS80-H in the UT (blue anomalies in figures). The time lag-induced wet bias anomalies are observed to increase in magnitude with decreasing temperature, leading to $\sim 10 \% \mathrm{RH}$ overshoots near sharp RH gradients in the UT. This effect can be partly removed with the TLC (not shown here), but adding the TDC correction leads to severe overcorrection in the UT (similar to that in Fig. 4). These time lag effects are seen more clearly in Fig. 5 as large positive anomalies coincident with dry layers (blue anomalies). The same figure shows that the RS80- $\mathrm{H}$ has no bias, on average, below an altitude of $4 \mathrm{~km}$. Above that, the uncorrected RS80-H seems to have a slight wet bias in the MT and UT. (The corrected RS80-H is not shown in Fig. 5.) Miloshevich et al. (2006) discussed the point that the TLC reveals the wet bias in the original calibration of the RS80-H. The findings presented here support this claim, but also do not encourage one to apply a TDC to the RS80-H in atmospheric conditions similar to that during LAUTLOS. 


\section{5) $\mathrm{RS} 80-\mathrm{A} / \mathrm{RS} 80-\mathrm{H}$}

According to Fig. 9, both TLC methods, by MOL and Miloshevich, seem to considerably improve the fit with the NOAA-FPH; they especially help in observing the UT/LS water vapor more accurately with the RS80. This improvement may be of importance in studies of troposphere-stratosphere exchange. The remaining time lag error is clearly smaller for the RS80-A than it is for the RS80-H. However, it also is clear that the RS80-H benefits more from the use of the TLC. The TLCs for the RS80-A by both the Miloshevich and the MOL correction schemes seem comparable; the differences seem to arise from the TDCs.

If the performances of the original, uncorrected RS80-A and RS80-H are compared, it is clear that the RS80-A has the largest dry bias inside cirrus. This is because the RS80-H has a better calibration modeling applied than does the RS80-A. On the other hand, the RS80-A clearly has a smaller time lag compared to the $\mathrm{RS} 80-\mathrm{H}$, as was discussed in sections $2 \mathrm{a}$ and 3 . The original RH profiles of the RS80 are not shown in Fig. 9 to avoid cluttering the profiles; however, they were shown earlier in Fig. 2, as an example of the correction efficiency.

\section{c. Sensor behavior inside clouds (examples)}

The first example (Fig. 10) relates to ice contamination of the RS80-A and the daytime version of the Snow White. During the day sounding on 21 February 2004, the LAUTLOS payload went through thick MT cloud situated between 3 and $7 \mathrm{~km}$. The temperature inside the cloud ranged from $-20^{\circ}$ to $-45^{\circ} \mathrm{C}$, which allows us to assume mixed-phase conditions in the lower parts of the cloud. Above the cloud layer, in the UT, is another moist layer. This, however, is clearly subsaturated.

The cloud penetration caused the RS80-A to lose its sensitivity to sudden changes in the ambient RH. This is seen at an altitude of $7 \mathrm{~km}$, where the other, heated Humicaps experience a dry layer above the cloud. This kind of feature is observable as a positive anomaly in the intercomparisons, if not removed. It seems, though, that the ice evaporated from the RS80-A Humicap before reaching the tropopause, since it was capable of registering the sudden drop in $\mathrm{RH}$ above it. In the UT it is difficult to say whether the RS80-A measurement in the humid layer at $9 \mathrm{~km}$ is disturbed or not; however, the MOL seems to correct the dry bias in it.

In this case (Fig. 10), the performances of the FN, RS90, and the daytime version of the Snow White are comparable to the case shown in Fig. 8 with the following differences: 1) the biases of the FN and RS90 are

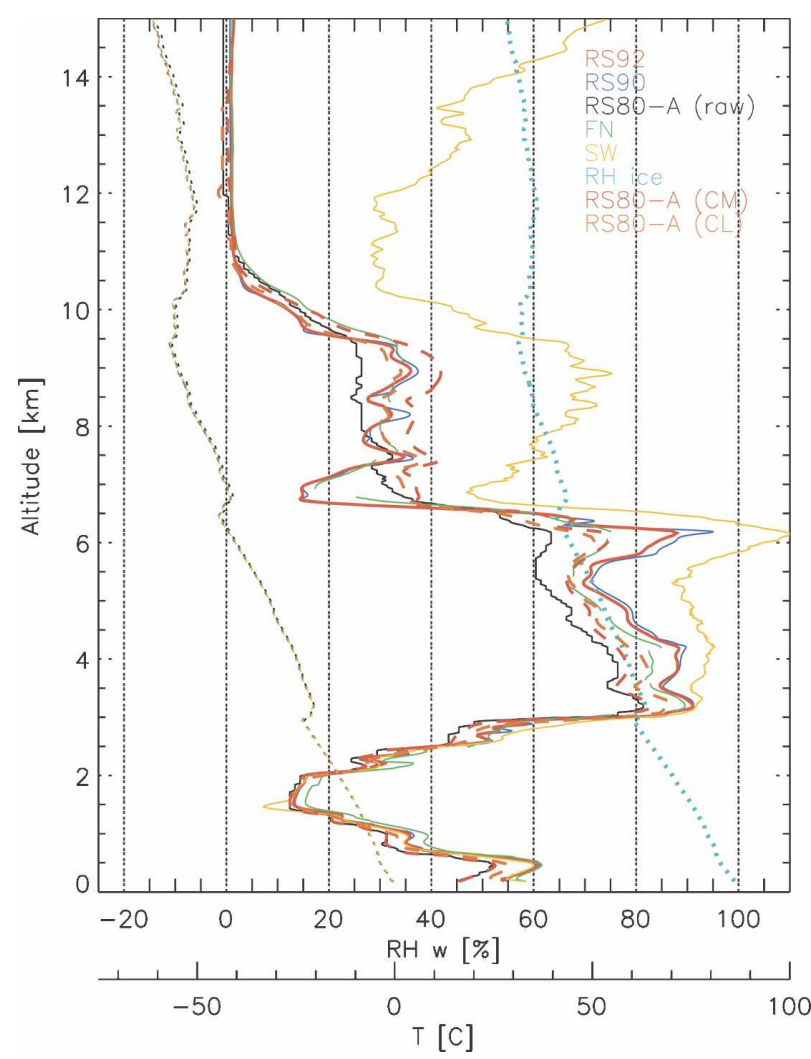

FIG. 10. A cloud penetration example. The plot key is as in Fig. 8.

smaller in the UT, since this positive $\mathrm{RH}$ anomaly is clearly in an ice-subsaturated environment (actually, the agreement between the RS90 and the RS92 is remarkable); and 2) the Snow White measurement is ruined by an increasing wet bias above the MT cloud base due to contamination problems. Unfortunately, this is typical in the cloudy LAUTLOS dataset.

In addition, it must be mentioned that the FN dry bias, in ice-supersaturated conditions, and the wet bias, in dry layers, are both enhanced by the lacking TLC. This finding again suggests that the FN would benefit from the TLC if it were available.

The second example (Fig. 11) presents a case of ice contamination of the RS80, in which it does not recover before the tropopause. The effects of ice contamination can be observed in the lower stratosphere as a long tail of tropospheric $\mathrm{RH}$ values up to an altitude of $15 \mathrm{~km}$. Such a tail of unrealistically high $\mathrm{RH}$ values can be used to trace ice-contaminated soundings in datasets. Icecontaminated data are removed from the statistics in section 5. The same applies with Snow White contamination problems, which are evident in this example above the 7-km level. 


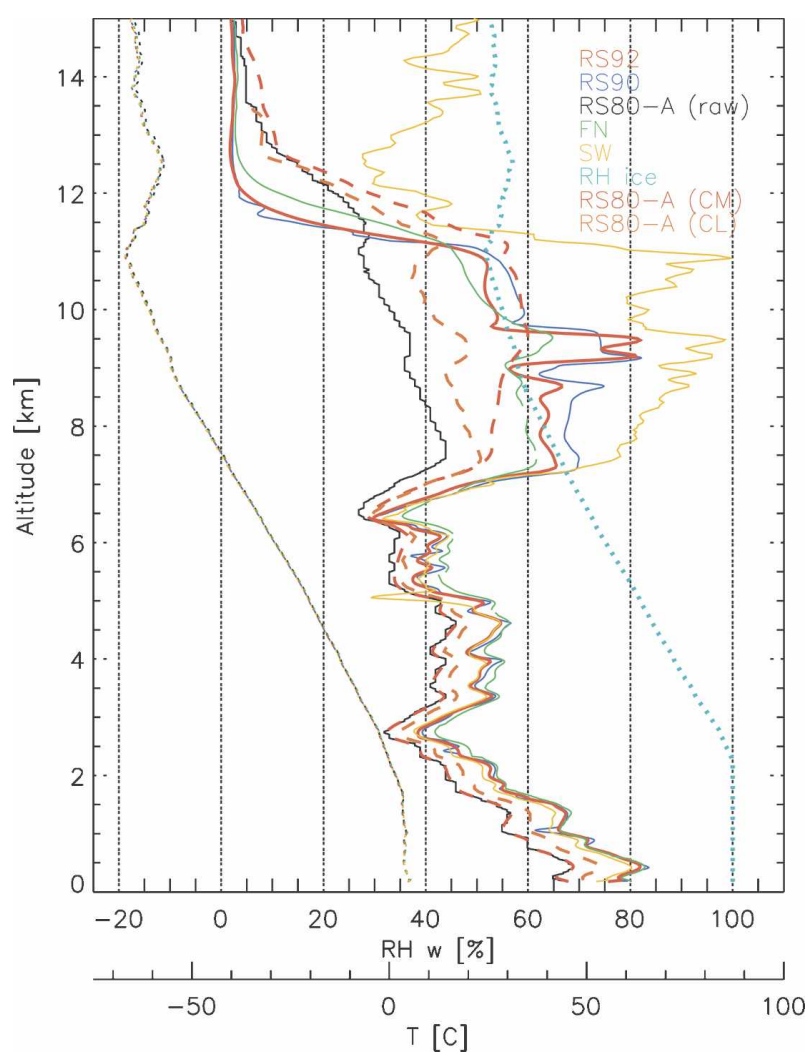

FIG. 11. An RS80-A and Snow White (daytime version) ice contamination case. The plot key is as in Fig. 8.

\section{d. Humicap development}

The presented results summarize the developments that have taken place in the Humicap by demonstrating the typical consistency differences and improvements in the RS80-A, RS80-H, RS90, and RS92 RH measurements during the past two decades. The paper of Miloshevich et al. (2006) presents the RH performance of the RS92 radiosonde; however, the RS92 used at that time did not have the latest version of the RH sensor TD correction, neither did it include the new design for minimizing solar heating of the RH sensor. The improvements in radiosonde $\mathrm{RH}$ measurements can also be seen from satellite data analysis. A study of the European radiosonde station data in 2002-03 as compared with satellite data (John and Buehler 2005) indicates that the U.K. stations clearly have a smaller RH bias than the other stations. This is due to the fact that the United Kingdom is using the RS80 H-polymer sensor, while others mainly use the RS80-A. The difference between the RS90 and RS80-A was not found to be so pronounced. This may be because of the chemical contamination, which was not eliminated in the RS90, and due to solar radiation effects on the sensor.

\section{Summary and conclusions}

The LAUTLOS-WAVVAP experiment aimed to characterize the temperature-dependent errors in radiosonde relative humidity (RH) measurements and to test the available corrections. The comparisons included radiosondes (RS80-A, RS90, RS92, and FN) and reference hygrometers (NOAA-FPH, CU-CFH, Snow White, and FLASH-B). The environment typified highlatitude winter conditions. Tropopause temperatures were around $-70^{\circ} \mathrm{C}$ during the campaign.

The night comparisons of the reference instruments with the radiosondes showed that, in the troposphere, the RS92 agrees best with the NOAA-FPH. The differences in the mid- (MT) and lower troposphere (LT) generally lay between $\pm 5 \% \mathrm{RH}$. In the temperature $(T)$ interval of $-20^{\circ}$ to $-55^{\circ} \mathrm{C}$, there was actually no bias at all. In the upper troposphere (UT), or more precisely for $T<-55^{\circ} \mathrm{C}$, the RS92 seems to have a wet bias of $\sim 5 \% \mathrm{RH}$. It was shown that this was partly due to the time lag error in the RS92, and possibly due to the termination of its heating cycle at $-40^{\circ} \mathrm{C}$. The RS92 was chosen as the working reference for the LAUTLOS radiosonde comparison.

The Snow White was found to be in good agreement with the RS92, and especially with the NOAA-FPH. However, the Snow White data had to be first "cleaned" properly, because the daytime version of the Snow White has severe problems with water contamination in the UT. It is therefore recommended that Snow White data are scrutinized and edited before making any comparisons.

It was seen that the lower limit of FLASH-B measurements is around $7 \mathrm{~km}$; this instrument is therefore not optimal for tropospheric measurements. Stratospheric comparisons showed a good agreement between NOAA-FPH and FLASH-B (Vömel et al. 2007c). Radiosondes cannot yet succeed in reproducing the profiles of these reference class hygrometers in the stratosphere. There RS92 and FN had a dry bias of more than $50 \%$; on the other hand, this translates to differences of only a couple of ppmv or $0.5 \%$ to $1.5 \% \mathrm{RH}$.

The radiosonde comparison showed that the FN agrees best with the RS92 in having no visible average bias, but these sondes do disagree under certain conditions. In general, the size of the disagreement is mainly dependent on temperature, and its sign on the distance from the ice-saturated $\mathrm{RH}$ value. More precisely, for $T$ $<-30^{\circ} \mathrm{C}$ and at high humidities $(70 \%-50 \% \mathrm{RH})$, the FN shows a $2 \%-6 \%$ lower RH than the RS92. On the other hand, for $T<-30^{\circ} \mathrm{C}$ and at lower humidities 
$(40 \%-20 \% \mathrm{RH})$ the $\mathrm{FN}$ gives a $2 \%-4 \%$ higher $\mathrm{RH}$ than the RS92.

For $T \ll 0^{\circ} \mathrm{C}$, the RS90 has a positive bias compared to the RS92. The difference is clearly temperature dependent, and the RS90 wet bias seemed to increase semilinearly with decreasing temperature in conditions near to saturation. The bias was larger in high $\mathrm{RH}$, when it increases from $\sim 0 \% \mathrm{RH}$ at $0^{\circ} \mathrm{C}$ to up to $\sim 10 \%$ $\mathrm{RH}$ at $-60^{\circ} \mathrm{C}$. In low ambient $\mathrm{RH}$ conditions, the bias is only a few percent $\mathrm{RH}$; however, in terms of relative difference the error is not $\mathrm{RH}$ dependent.

The RS80-A has a dry bias throughout the troposphere, increasing toward low temperatures. The RS80-A dry bias is at its largest in humid UT conditions, where it can be even as high as $30 \% \mathrm{RH}$ (at $T \gg$ $-60^{\circ} \mathrm{C}$ ). For $T>-30^{\circ} \mathrm{C}$, the dry bias is $\sim 5 \pm 5 \% \mathrm{RH}$, depending on the ambient $\mathrm{RH}$.

The observed bias in the RS80-A could be reduced significantly at all altitudes with the correction algorithm developed by Leiterer et al. (2000). It was shown that, when using this correction, for $T>-30^{\circ} \mathrm{C}$, that is, in the LT and MT, the dry bias in the RS80-A RH vanished. For $T<-30^{\circ} \mathrm{C}$, and at high $\mathrm{RH}$, the bias did diminish considerably, but on average there still remained a $\sim 5 \%$ RH dry bias in the UT. The maximum dry bias values were diminished to $<15 \mathrm{RH}$ percentage units. According to the average bias, the temperature dependence was almost fully removed. The second tested correction approach for RS80-A bias (Miloshevich et al. 2001) tends to overcorrect in high $\mathrm{RH}$ conditions when $T<-50^{\circ} \mathrm{C}$, while above $-30^{\circ} \mathrm{C}$ it is ineffective, leaving the RS80-A dry bias uncorrected in the LT. The latter result suggests that it is not optimal for a cloudy atmosphere.

The RS80-H does not suffer from bias errors as badly as the RS80-A does. This difference is an important fact that should be taken into account when using RS80 RH records. However, the real issue with the RS80-H is its rather large time lag error, which can be successfully reduced, if high-resolution data are available, using the correction provided by Miloshevich et al. (2004).

Time lag-corrected radiosondes achieved better agreement with the frost-point hygrometers. Applying the TLC seemed to improve the measurement accuracy, especially in the UT. This improvement may be of importance in studies of troposphere-stratosphere exchange.

As a general remark, because of the high-latitude winter conditions, these comparisons do not bring out the radiation effects on the instruments. The radiation dry bias in the RS92 is discussed in Vömel et al. (2007b).
Acknowledgments. Thanks are due to all the LAUTLOS participants and the FMI-ARC sounding crew for their efforts. Special thanks go to T. Turunen (FMI) for help in organizing the database and E. Kyrö (FMI) for useful discussions. In addition, Horst Dier (DWD) must be acknowledged for his work with the RS80-A correction algorithms. LAUTLOS-WAVVAP was hosted by the FMI Arctic Research Centre at Sodankylä, assisted by Vaisala Oyj as part of the Finnish contribution to the EU COST Action 723 project "The Role of the Upper Troposphere and Lower Stratosphere in Global change." The campaign was partly funded from the LAPBIAT Facility, which belongs to the EU program: "Access to Research Infrastructures" (http://www.sgo.fi/lapbiat/).

\section{APPENDIX}

\section{List of Acronyms}

CL Corrected with the MOL TDC algorithm (in plot legends)

CM Corrected with the Miloshevich TDC algorithm (in plots legends)

FPH Frost-point hygrometer

FN Method of standardized frequencies

GC MOL ground check correction

LS Lower stratosphere

LT Lower troposphere

MOL Method of Lindenberg, an RH correction scheme for the RS80-A

MT Midtroposphere

RH Relative humidity

TD Temperature dependence

TDC Temperature dependence correction

TLC Time lag correction

UT Upper troposphere

\section{REFERENCES}

Deuber, B., and Coauthors, 2005: Middle Atmospheric Water Vapour Radiometer (MIAWARA): Validation and first results of the LAPBIAT Upper Tropospheric Lower Stratospheric Water Vapour Validation Project (LAUTLOS-WAVVAP) campaign. J. Geophys. Res., 110, D13306, doi:10.1029/ 2004JD005543.

Forster, P., and K. Shine, 2002: Assessing the climate impact of trends in stratospheric water vapor. Geophys. Res. Lett., 29, 1086, doi:10.1029/2001GL013909.

Fujiwara, M., M. Shiotani, F. Hasebe, H. Vömel, S. J. Oltmans, P. W. Ruppert, T. Horinouchi, and T. Tsuda, 2003: Performance of the Meteolabor "Snow White" chilled-mirror hygrometer in the tropical troposphere: Comparisons with the Vaisala RS-80 A/H-Humicap sensors. J. Atmos. Oceanic Technol., 20, 1534-1542.

Hyland, R., and A. Wexler, 1983: Formulations for the thermo- 
dynamic properties of the saturated phases of $\mathrm{H}_{2} \mathrm{O}$ from 173.15K to $473.15 \mathrm{~K}$. ASHRAE Trans., 89, 500-519.

John, V. O., and S. A. Buehler, 2005: Comparison of microwave satellite humidity data and radiosonde profiles: A survey of European stations. Atmos. Chem. Phys., 5, 1529-1550.

Leiterer, U., H. Dier, and T. Naebert, 1997: Improvements in radiosonde humidity profiles using RS80/RS90 radiosondes of Vaisala. Contrib. Atmos. Phys., 70, 319-336.

, - - D. Nagel, T. Naebert, D. Althausen, and K. Franke, cited 2000: Method for correction of RS80 A-Humicap humidity profiles. [Available online at http://www.metoffice.gov.uk/research/interproj/radiosonde/reports/leiterer. pdf.]

— D. Althausen, K. Franke, A. Katz, and F. Wegner, 2005: Correction method for RS80-A Humicap humidity profiles and their validation by lidar backscattering profiles in tropical cirrus clouds. J. Atmos. Oceanic Technol., 22, 18-29.

Miloshevich, L., H. Vömel, A. Paukkunen, A. J. Heymsfield, and S. J. Oltmans, 2001: Characterization and correction of relative humidity measurements from Vaisala RS80-A radiosondes at cold temperatures. J. Atmos. Oceanic Technol., 18, 135-156.

- A. Paukkunen, H. Vömel, and S. Oltmans, 2002: Impact of Vaisala radiosonde humidity corrections on ARM IOP data. Proc. 12th Atmospheric Radiation Measurement (ARM) Science Team Meeting, St. Petersburg, FL, U.S. Department of Energy, 251-258. [Available online at http://www. arm.gov/publications/proceedings/conf12/extended_abs/ miloshevich-lm.pdf.]

,,--- , and,- 2004 : Development and validation of a time-lag correction for Vaisala radiosonde humidity measurements. J. Atmos. Oceanic Technol., 21, 1305-1327.

—, H. Vömel, D. Whiteman, B. Lesht, F. Schmidlin, and F. Russo, 2006: Absolute accuracy of water vapor measurements from six operational radiosonde types launched during AWEX-G, and implications for AIRS validation. J. Geophys. Res., 111, D09S10, doi:10.1029/2005JD006083.

Nagel, D., U. Leiterer, H. Dier, A. Kats, J. Reichhardt, and A. Behrendt, 2001: High accuracy humidity measurements using the standardized frequency method in a research upper-air sounding system. Meteor. Z., 10, 395-405.

Nash, J., R. Smout, T. Oakley, P. Pathack, and S. Kurnosenko, cited 2005: WMO intercomparison of high quality radiosonde systems, Vacoas, Mauritius, 2-25 February 2005. WMO Commission on Instruments and Methods of Observation, Final Rep., 118 pp. [Available online at http://www. wmo.ch/pages/prog/www/IMOP/reports/2003-2007/ RSO-IC-2005_Final_Report.pdf.]

Paukkunen, A., 1995: Sensor heating to enhance reliability of radiosonde humidity measurement. Proc. 11th Conf. on Interactive Information and Processing Systems for Meteorology, Oceanography, and Hydrology, Dallas, TX, Amer. Meteor. Soc., 103-106.

, V. Antikainen, and H. Jauhiainen, 2001: The accuracy and performance of the new Vaisala RS90 radiosonde in operational use. Proc. 11th Symp. on Meteorological Observations and Instrumentation, Albuquerque, NM, Amer. Meteor. Soc., 4.5 .

Revercomb, H. E., and Coauthors, 2003: The ARM program's water vapor intensive observation periods. Bull. Amer. Meteor. Soc., 84, 217-236.

Turner, D. D., B. M. Lesht, S. A. Clough, J. C. Liljegren, H. E. Revercomb, and D. C. Tobin, 2003: Dry bias and variability in Vaisala RS80-H radiosondes: The ARM experience. $J$. Atmos. Oceanic Technol., 20, 117-132.

Vasic, V., D. Feist, S. Muller, and N. Kampfer, 2005: An airborne radiometer for stratospheric water vapor measurements at 183 GHz. IEEE Trans. Geosci. Remote Sens., 43, 1563-1570.

Vaughan, G., C. Cambridge, L. Dean, and A. Phillips, 2005: Water vapour and ozone profiles in the midlatitude upper troposphere. Atmos. Chem. Phys., 5, 963-971.

Vömel, H., S. J. Oltmans, D. J. Hofmann, T. Deshler, and J. M. Rosen, 1995: The evolution of the dehydration in the Antarctic stratospheric vortex. J. Geophys. Res., 100, 13919 13926.

_, M. Fujiwara, M. Shirotami, F. Hasebe, S. J. Oltmans, and J. E. Barnes, 2003: The behavior of the Snow White chilledmirror hygrometer in extremely dry conditions. J. Atmos. Oceanic Technol., 20, 1560-1567.

— D. David, and K. Smith, 2007a: Accuracy of tropospheric and stratospheric water vapor measurements by the cryogenic frost point hygrometer: Instrumental details and observations. J. Geophys. Res., 112, D08305, doi:10.1029/ 2006JD007224.

— and Coauthors, 2007b: Radiation dry bias of the Vaisala RS92 humidity sensor. J. Atmos. Oceanic Technol., 24, 953 963.

_ V. Yushkov, S. Khaykin, L. Korshunov, E. Kyrö, and R. Kivi, 2007c: Intercomparisons of stratospheric water vapor sensors: FLASH-B and NOAA/CMDL frost-point hygrometer. J. Atmos. Oceanic Technol., 24, 941-952.

Wang, J., H. L. Cole, D. J. Carlson, E. R. Miller, K. Beierle, A. Paukkunen, and T. K. Laine, 2002: Corrections of humidity measurement errors from the Vaisala RS80 radiosondeApplication to TOGA COARE data. J. Atmos. Oceanic Technol., 19, 981-1002.

Yushkov, V., V. Astakhov, and S. Merkulov, 1998: Optical balloon hygrometer for upper-troposphere and stratosphere water vapor measurements. Proc. SPIE, 3501, 439-445.

—, S. Merkoulov, V. Astakhov, J. P. Pommereau, and A. Garnier, 2000: A Lyman alpha hygrometer for long duration IR Montgolfier during the Lagrangian-THESEO experiment. Stratospheric Ozone 1999, Proc. Fifth European Symp. on Stratospheric Ozone, EC Air Pollution Research Rep. 73, Saint-Jean de Luz, France, European Commission, 400-403. , and Coauthors, 2005: Vertical distribution of water vapor in Arctic stratosphere based on LAUTLOS field campaign in January-February 2004. Izv. Fiz. Atmos. I Okeana, 41, 1-9. 